\title{
Magnetic properties of Fe nanowires electrodeposited in self-ordered alumina membrane
}

\author{
Własności magnetyczne nanodrutów Fe \\ osadzonych elektrolitycznie \\ w samouporządkowanej membranie tlenku glinu
}

\begin{abstract}
The iron nanowire arrays (NWs) were fabricated by DC electrodeposition into hexagonally ordered alumina pores. With the use of X-ray diffraction analysis, the structure of iron wires was determined. The iron wires have the Body Centered Cubic structure. The influence of cathodic deposition potential and parameters of membrane on the magnetic properties of nanowire arrays was investigated. Magnetic properties analyzed by VSM measurements suggest that the easy axis of magnetization follows the nanowire axis, with coercivity increasing with a decrease of nanowire diameter and length. The dependence of the height of Fe wires on the electrodeposition potential was determined. The low cathodic potential and smaller pore diameter are the synthesis parameters most beneficial for large coercivity with easy axis along nanowires.
\end{abstract}

Keywords: anodic alumina membrane, hysteresis loop, iron, nanowires

\section{Streszczenie}

Nanodruty żelaza (NWs) zostały wytworzone w procesie elektrolitycznego osadzania w warunkach potencjostatycznych w heksagonalnie uporządkowanych porach tlenku glinu. Za pomocą rentgenowskiej analizy dyfrakcyjnej określono strukturę drutów żelaznych. Nanodruty żelazne wykazują strukturę regularną przestrzennie centrowaną (RPC). Zbadano wpływ potencjału katodowej redukcji oraz parametrów membrany na własności magnetyczne układu nanodrutów. Własności magnetyczne analizowane za pomocą pomiarów VSM sugerują, że łatwa oś magnetyzacji znajduje się wzdłuż osi drutów, a pole koercji wzrasta wraz ze spadkiem średnicy i długości nanodrutów. Określono zależność wysokości drutów Fe od potencjału elektroosadzania. Niski potencjał katodowej redukcji oraz mniejsza średnica porów to najbardziej korzystne parametry syntezy dla uzyskania wysokiej koercji z łatwą osią magnetyzacji wzdłuż osi nanodrutów.

Słowa kluczowe: membrana tlenku glinu, pętla histerezy, żelazo, nanodruty

Iwona Dobosz, Wanda Gumowska: AGH University of Science and Technology, Faculty of Non-Ferrous Metals, Department of Physical Chemistry and Metallurgy of Non-Ferrous Metals, Krakow, Poland; Maciej Czapkiewicz: AGH University of Science and Technology, Faculty of Computer Science, Electronics and Telecommunications, Department of Telecommunications, Krakow, Poland; iwona.dobosz@agh.edu.pl 


\section{Introduction}

Over the last two decades, electrochemical syntheses of metallic nanowires within the pores of porous membranes (for example polycarbonate and anodic alumina membrane) have attracted considerable attention because of their optical [1], electronic [2] magnetic properties $[3,4]$ and potential for nanotechnological applications. The idea of employing a membrane as a template for fabrication of metallic nanowires by electrodeposition process is considered as an alternative solution to overcoming the difficulty of fabricating fibrils with very small diameters by lithographic methods [5].

Membrane parameters, electrodeposition parameters, selection of metal as well as membrane preparation strongly affect the nanowire properties. Many studies have been performed to determine the magnetic properties of metal nanowires [6-8]. The studies show both an increase $[9,10]$ and a reduction $[11,12]$ of coercivity value with a decrease in nanowire diameter and length occurred with an easy axis of magnetization along nanowires. Membrane parameters can also affect the crystalline structure of nanowires [13]. Some studies show that the electrodeposition parameters, such as electrolyte composition, temperature, $\mathrm{pH}$ or cathodic potential, influence the structure and magnetic properties of nanowires [14-16]. The concentration of metal ions, as well as the addition of a buffering factor can show a positive effect on the magnetic properties of the nanowires [14].

The magnetic properties of a nanowire can be induced, among other things, by the selection of a metal or alloy. The high saturation magnetization $\left(M_{s}\right)$ materials, such as Fe (2.2 T) and CoFe (2.4 T) can achieve a sufficiently high shape anisotropy [17]. Moreover, iron exhibits low cubic magnetocrystaline anisotropy, allowing improvement of the magnetic anisotropy to be obtained by means of the selection of optimum material geometry. The total anisotropy represents the competition among magnetocrystaline, shape and magnetoelastic anisotropies and dipolar interaction [18]. Magnetoelastic anisotropy, originating from external stress on the ferromagnetic material, may also affect the direction of the favored magnetization. The low porosity value and high misalignment of nanowires reduce dipolar interaction between nanowires, also strongly influencing the magnetic properties.

Fe nanowires exhibit high magnetic coercivity resulting from the shape anisotropy and orientation of nanowire assemblies, nonetheless only a few publications have reported the morphology of Fe nanowires $[3,17,19]$. In this paper, the deposition conditions which need to be improved, such as the potential and pore diameter of the membrane, were examined.

\section{Experiment}

The aluminum composition and detailed information about the process of the preparation of samples for the anodic oxidation process have been presented in an earlier paper [20]. 
The process of anodic oxidation was carried out in two stages. The anodic alumina was formed at a constant voltage in the two solutions: $0.3 \mathrm{M}$ oxalic acid at $2^{\circ} \mathrm{C} ; 0.17 \mathrm{M}$ phosphoric acid $(\mathrm{V})$ at $-1^{\circ} \mathrm{C}$. The time of the first anodizing for oxalic acid solutions was 24 hours, whereas for the orthophosphoric acid -2 hours. After the first anodizing stage, the oxide film was removed by immersing the samples into the solution of the composition: $0.6 \mathrm{M} \mathrm{H}_{3} \mathrm{PO}_{4} ; 0.2 \mathrm{M} \mathrm{CrO}_{3}$, at $80^{\circ} \mathrm{C}$ for 2 hours. After removal of the oxide film, the samples were subjected to the second anodizing stage under the same conditions as the first one. The time of the anodizing oxidation process affects the thickness of the oxide films. The second anodizing process for the solutions of oxalic and orthophosphoric acids lasted for 6 , and 10 hours, respectively. After the two anodizing stages, the aluminum substrate was removed in the mixture of the $0.2 \mathrm{M} \mathrm{HCl}$ and $0.1 \mathrm{M} \mathrm{CuCl}_{2}$ solution in order to open pores. The barrier layer on the sample bottom was etched in $0.86 \mathrm{M} \mathrm{H}_{3} \mathrm{PO}_{4}$ at $30^{\circ} \mathrm{C}$. After the removal of both the aluminum and the barrier layer, a thin film of gold was sprayed onto the sample surface from the side of the open pores in order to provide an electric contact during the process of the electrodeposition of nanowires. In the areas from which the aluminum substrate was removed, a film of cooper was deposited by means of electrolysis in potentiostatic conditions. The diagram of the electrolyzer used in the experiment and the methodology of the preparation of the membrane is provided in detail in the paper [21].

The alumina membranes of a nanoporous and ordered structure with defined pore dimensions (diameter, height, distance between them) were obtained. During the electrolysis process, Fe was deposited cathodically in the pores of the obtained membranes. The process carried out from sulfate solutions of the composition: $0.5 \mathrm{M} \mathrm{FeSO}_{4}$; $0.3 \mathrm{M} \mathrm{H}_{3} \mathrm{BO}_{3} ; 0.25 \mathrm{M} \mathrm{C}_{6} \mathrm{H}_{8} \mathrm{O}_{6}$. The $\mathrm{pH}$ value of the solution was 3 and it was controlled by adding sulfuric acid $(\mathrm{VI})$ or sodium hydroxide. All experiments were carried out at room temperature in the three-electrode system, where a saturated calomel electrode was used as a reference (SCE, $0.241 \mathrm{~V} v$ v. SHE). All the potentials were recorded in relation to the SCE electrode, and then converted and presented with reference to the standard hydrogen electrode (SHE). A platinum plate was used as the counter electrode. The area of the working electrode surface was $0.785 \mathrm{~cm}^{2}$. The experiment was carried out with "Autolab" potentiostat. The potential was selected on the basis of the chronoamperometric and cycling voltamperometry experiments [21].

The morphology of the oxide films and their cross-sections were observed with the use of the high resolution scanning microscopy technique with the field emission. The scanning microscope (HITACHI S- $4700^{\circ}$ ) was equipped with an EDS system for chemical composition analysis (NORAN VANTAGE). Structural studies were carried out with the use of the X-ray diffractometer (BRUKER AXS "Discover 8 ") and filtered $\mathrm{Cu}_{\mathrm{k \alpha}}$ radiation. The investigation of the magnetic hysteresis loop and its parameters (coercivity, saturation field, saturation magnetization and the remanence) was conducted with the use of the Resonance Vibrating Sample Magnetometer (R-VSM) in the magnetic field directed both perpendicular and parallel to the wire axis. 


\section{Results}

\subsection{The influence of the cathodic deposition potential}

The electrodeposition of Fe nanowire arrays was carried out in the membrane pores at the following dimensions: the diameter of the pores $D_{p}=70 \mathrm{~nm}$, the distance between the pores $D_{c}=110 \mathrm{~nm}$. During the electrodeposition process, different potentials were applied: $-0.8 \mathrm{~V} ;-1.0 \mathrm{~V} ;-1.1 \mathrm{~V}$ and $-1.2 \mathrm{~V}$ (vs. SHE). The time of electrolysis was kept constant and equaled 35 minutes. The relationship between the height $(L)$ of the obtained nanowires and cathodic potential deposition $(E)$ is shown in Table 1 and Figure 1. The results obtained in the measurements show that the height of the Fe nanowires is significantly dependent on the potential of electrodeposition.

Table 1. The dependence of the height of iron wires on the cathodic potential deposition

\begin{tabular}{|c|c|}
\hline Cathodic potential [V] (vs. SHE) & Height $[\boldsymbol{\mu m}]$ \\
\hline-0.8 & $0.5 \pm 0.2$ \\
\hline-1.0 & $10 \pm 0.43$ \\
\hline-1.1 & $16.4 \pm 0.65$ \\
\hline-1.2 & $31.7 \pm 0.91$ \\
\hline
\end{tabular}

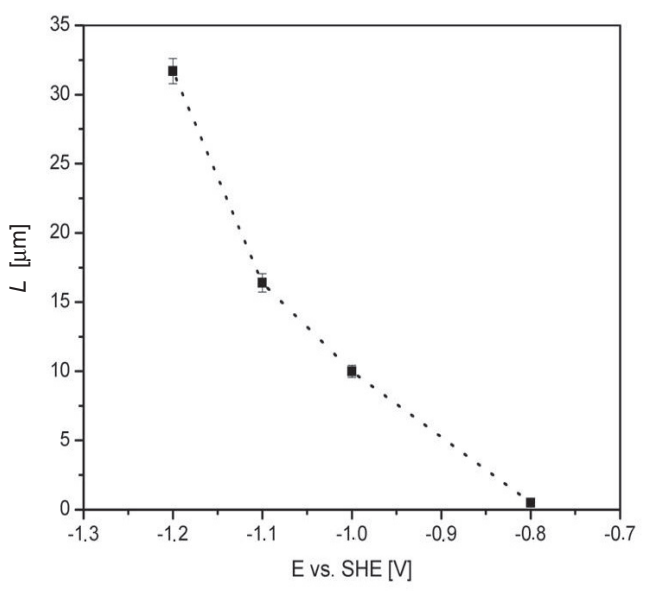

Fig. 1. Influence of the cathodic potential on the height of the Fe nanowires. Dimensions of the membrane pores: $D_{p}=70 \mathrm{~nm}, D_{c}=110 \mathrm{~nm}$

The obtained materials were observed with the use of the scanning microscopy technique (SEM). Figure 2 shows an exemplary photo of the Fe nanowire arrays deposited in the pores of the $\mathrm{Al}_{2} \mathrm{O}_{3}$ membrane (the height of the nanowires $L \approx 10 \mu \mathrm{m}$ ). 


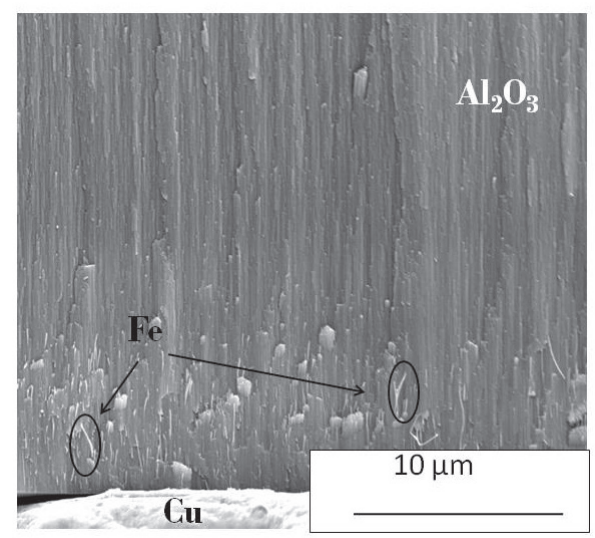

Fig. 2. A SEM microphoto of the Fe NWs deposited in the pores of membrane with the dimensions: $D_{p}=70 \mathrm{~nm}, D_{c}=110 \mathrm{~nm}$ at the potential $-1.0 \mathrm{~V}(\mathrm{vs}$. SHE). The height of the wires was about $10 \mu \mathrm{m}$

The SEM investigation shows that the formation of wires starts in the lower part of the $\mathrm{Al}_{2} \mathrm{O}_{3}$ membrane.

We used X-ray diffraction analysis to study the crystallographic structure of iron nanowires. In the diffractogram (Fig. 3), clear reflections characteristic for the Fe of the crystallographic indices (100), (211) can be seen. On the basis of the X-ray analysis it was found that the iron wires of the bcc structure had been built in the pores of the alumina membrane.

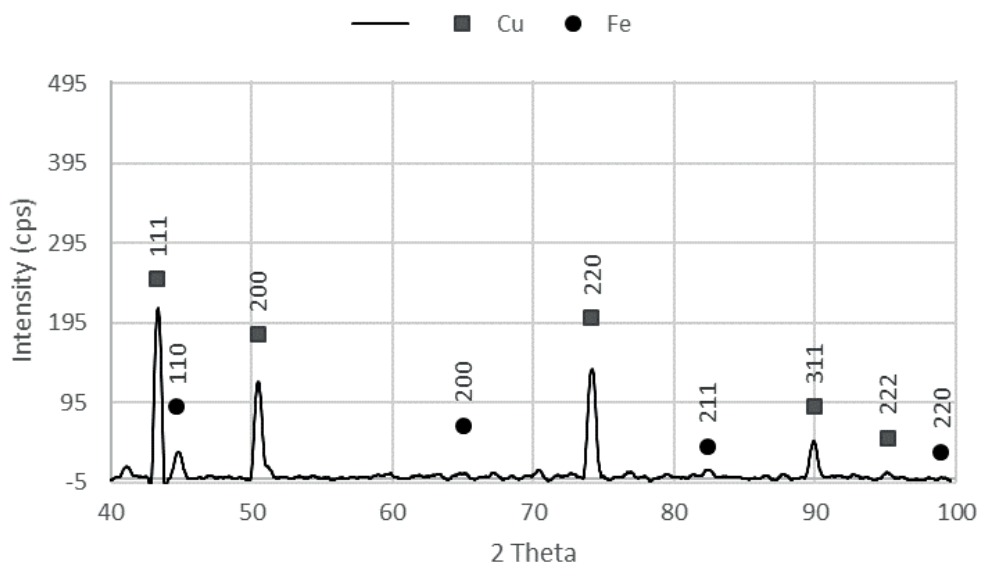

Fig. 3. X-ray phase analysis of the iron nanowire arrays obtained at the potential-1.0 V (Vs. SHE). The peaks characteristic for the iron and cooper are described with the indices of crystallographic planes 
The magnetic properties of the iron NWs deposited at different potentials were investigated in the magnetic field directed both perpendicular and parallel to the wire axis with the use of the R-VSM vibration magneto meter. The hysteresis loops are presented as the relationship between the magnetization to saturation magnetization ratio $\left(M / M_{s}\right)$ and magnetic field strength $(H)$.

The effect of the cathodic potential (range from $-1.0 \mathrm{~V}$ to $-1.2 \mathrm{~V}$ ) vs. SHE) on the shape of the hysteresis loop is shown in Figures $4 \mathrm{a}-\mathrm{c}$ for $70 \mathrm{~nm}$ of nanowires. These results indicate that an easy axis of magnetization is arranged along nanowires.

a)

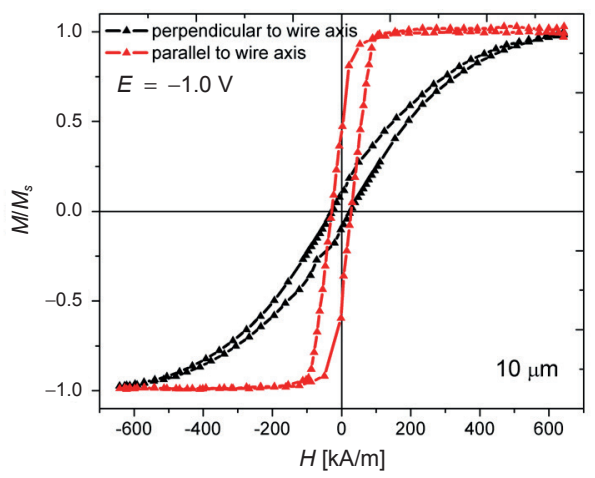

b)

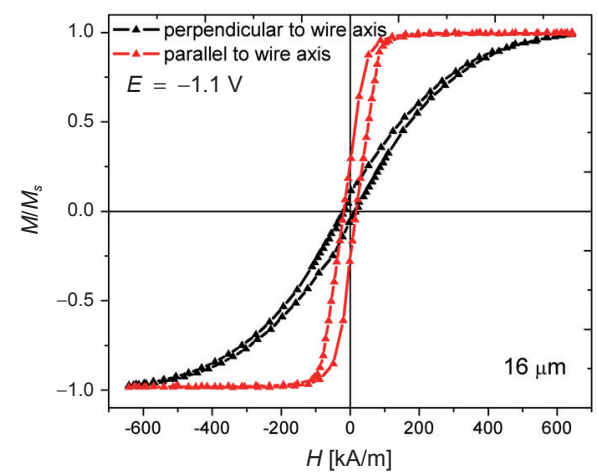

c)

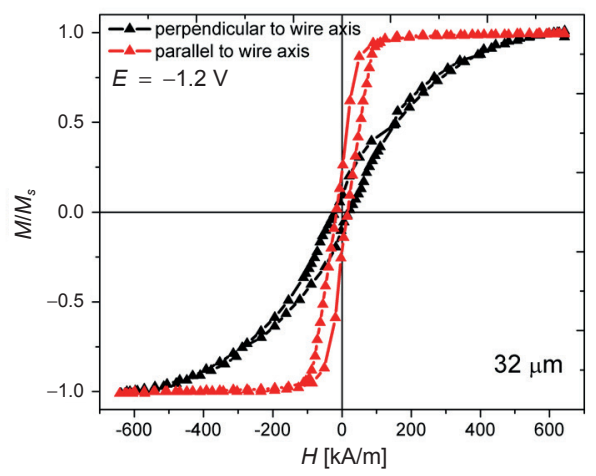

Fig. 4. The hysteresis loops of the iron NWs obtained in the process of the electrodeposition at different cathodic potential: a) $-1.0 \mathrm{~V} ; b)-1.1 \mathrm{~V} ; \mathrm{c})-1.2 \mathrm{~V}$ vs. SHE. The electrodeposition process was conducted in time 35 minutes. The iron nanowires with a diameter of $70 \mathrm{~nm}$

The values: magnetic field strength $(H)$, magnetization $(M)$, coercive field, coersivity $\left(H_{c}\right), M_{r} / M_{s}$ remanence squareness, where $M_{r}$ - residual magnetization (remanence), $M_{s}$ - saturation magnetization, volume energy density of remanence $\mu_{0} M_{r} H_{c}$ remanence energy $\mu_{0} M_{r} H_{c} \cdot V$, where $V$ is nanowires volume are presented in Table 2. 
Table 2. The values characterizing the magnetic properties of the iron NWs

\begin{tabular}{|c|c|c|c|c|c|c|c|c|c|c|}
\hline \multirow{3}{*}{$\begin{array}{c}E \\
{[V]}\end{array}$} & \multicolumn{2}{|c|}{$\begin{array}{c}\text { Remanent } \\
\text { energy density } \\
\mu_{0} M_{r} \cdot H_{c} \\
{\left[\mathbf{k J} / \mathbf{m}^{3}\right]}\end{array}$} & \multicolumn{2}{|c|}{$\begin{array}{c}\text { Remanence energy } \\
\mu_{0} M_{r} \cdot H_{c} \cdot V \\
{[J]}\end{array}$} & \multicolumn{2}{|c|}{$M_{r} / M_{s}$} & \multicolumn{2}{|c|}{$\begin{array}{c}\text { Remanence } \\
M_{r} \\
{\left[\mathrm{emu} / \mathrm{cm}^{3}\right]}\end{array}$} & \multicolumn{2}{|c|}{$\begin{array}{c}\text { Coercivity } \\
H_{c} \\
{[\mathrm{kA} / \mathrm{m}]}\end{array}$} \\
\hline & (II) & $(\perp)$ & $\begin{array}{c}(\text { III) } \\
\times 10^{-16}\end{array}$ & $\begin{array}{c}(\perp) \\
\times 10^{-16}\end{array}$ & (II) & $(\perp)$ & (II) & $(\perp)$ & (II) & $(\perp)$ \\
\hline & \multicolumn{10}{|c|}{ to wire axis } \\
\hline-1.0 & 28.4 & 5.77 & $\begin{array}{c}10.9 \\
(6.8 \mathrm{keV})\end{array}$ & $\begin{array}{c}2.22 \\
(1.39 \mathrm{eV})\end{array}$ & 0.48 & 0.10 & 826 & 168 & $\begin{array}{c}27.5 \\
(344 \text { Oe) }\end{array}$ & $\begin{array}{c}27.5 \\
(344 \text { Oe) }\end{array}$ \\
\hline-1.1 & 9.94 & 2.78 & $\begin{array}{c}6.11 \\
(3.82 \mathrm{keV})\end{array}$ & $\begin{array}{c}1.71 \\
(1.07 \mathrm{keV})\end{array}$ & 0.25 & 0.08 & 432 & 135 & $\begin{array}{c}18.4 \\
(230 \text { Oe) }\end{array}$ & $\begin{array}{c}16.5 \\
(206 \mathrm{Oe})\end{array}$ \\
\hline-1.2 & 7.65 & 3.65 & $\begin{array}{c}9.13 \\
(5.7 \mathrm{keV})\end{array}$ & $\begin{array}{c}4.35 \\
(2.72 \mathrm{keV})\end{array}$ & 0.22 & 0.09 & 379 & 147 & $\begin{array}{c}16.2 \\
(2020 \mathrm{e})\end{array}$ & $\begin{array}{c}19.8 \\
(248 \text { Oe) }\end{array}$ \\
\hline
\end{tabular}

The privileged magnetization direction is kept along the axis of wires (easy direction), whereas the field direction perpendicular to the wire axis of wires is the difficult direction. All samples demonstrate easy axis of magnetization along nanowire axis. We obtained the largest value of coercivity (344 Oe) for the nanowires deposited at a low cathodic potential $-1.0 \mathrm{~V}$ (Fig. $4 \mathrm{a}$ ), while at higher potentials $(-1.1 \mathrm{~V}$ and $-1.2 \mathrm{~V})$ we observed a smaller coercive field being $230 \mathrm{Oe}$ and 220 Oe, respectively. The decrease in the value of the coercive field along with the increase in the potential of wire deposition was also observed by other studies $[1,6,17]$. For the sample deposited at $-1.0 \mathrm{~V}$, independently of applied magnetization direction, the same value of coercivity $H_{c}=344 \mathrm{Oe}$ was observed.

This is confirmed by the evident differences in the remanence squareness between the magnetization curves. Along with the increase of the cathodic deposition potential, a decrease of the effective anisotropy was observed (Figs. 4a-c).

The relationship between the remanence squareness and the deposition potential of nanowires is presented in Figure 5. The remanence squareness measured perpendicularly to the sample plane (i.e. parallel to the wire axis) is higher when compared with the squareness for the magnetic field in the parallel direction to the sample plane. With the increase of cathodic potential (increase of wire length from $10 \mu \mathrm{m}$ at $-1.0 \mathrm{~V}$ up to $32 \mu \mathrm{m}$ at $-1.2 \mathrm{~V}$ ), a pronounced decrease from 0.48 to 0.22 of the squareness directed perpendicular to the sample surface is observed. The largest differences of the remanence squareness within the sample plane and perpendicularly to it are observed for the lower cathodic potential, i.e. $-1.0 \mathrm{~V}$ (Fig. 5). 


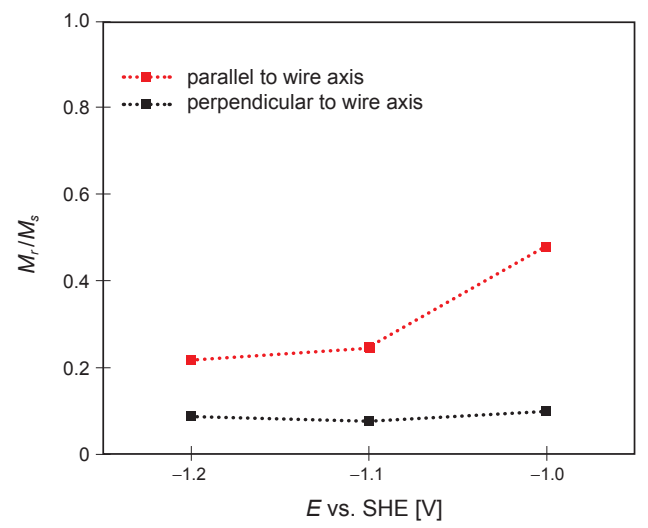

Fig. 5. The relationship between the remanence energy measured parallel and perpendicular to the wire axis and the deposition potential of the iron NWs deposited in the membrane of the dimensions: $D_{p}=70 \mathrm{~nm}, D_{c}=110 \mathrm{~nm}$

The cathodic deposition potential of Fe nanowire arrays significantly affects the morphology and magnetic properties. The increase of the cathodic potential turned out to have a disadvantageous influence on effective anisotropy and coercivity value. The easy magnetization direction is oriented along the wire axis. In other studies, it has been reported that an increase of the cathodic potential can enhance effective anisotropy and coercivity along nanowires [14, 17], as well as acting in the opposite way [6, 17].

\subsection{The influence of the pore diameter}

The electrodeposition of Fe wires was carried out with the use of membranes, the pore diameter of which are 70 and $100 \mathrm{~nm}$, whereas interpore distance are 110 and $250 \mathrm{~nm}$, respectively. In order to minimize the influence of the dipolar coupling between neighboring wires, the height of the wires was kept constant and amounted to $10 \mu \mathrm{m}$.

Figure 6 shows the magnetization curves for the iron nanowires deposited in these membranes. Furthermore, in Table 3, the values characterizing the magnetic field of the investigated nanowires are presented.

All samples demonstrate easy axis of magnetization along nanowire axis and square-like shape of loops. Along with the increase of pore diameters, a clear decrease of the coercive field (in both directions of the magnetic field) and the remanence is observed in the magnetic field direct parallel to the wire axis. We obtained the largest value of coercivity (344 Oe) and the largest squareness $(0.48)$ for the nanowires with the $70 \mathrm{~nm}$ pore diameter (Fig. 6a).

An increase of pore diameter changes the shape of loops measured for in-plane geometry, which get narrower. Moreover, towards the field perpendicular to the wire axis, a co-existence of both easy and difficult magnetization axis can be observed (Fig. 6b). 
a)

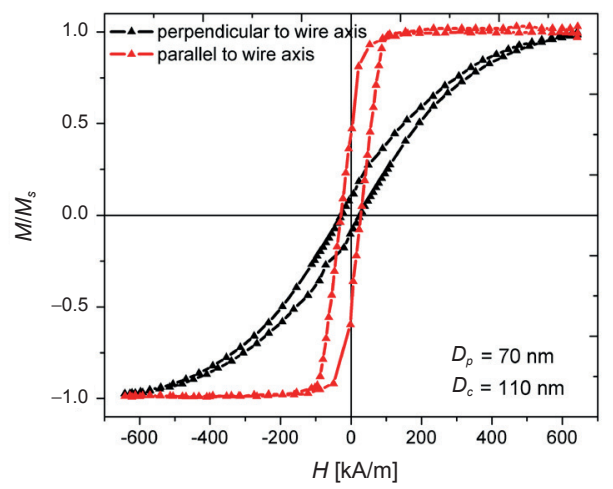

b)

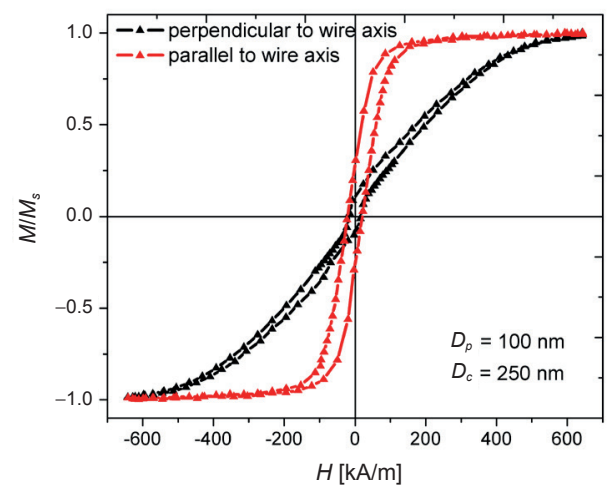

Fig. 6. The hysteresis loops for the iron nanowires of the diameters: a) $70 \mathrm{~nm}$; $b$ ) $100 \mathrm{~nm}$ obtained from the solution: $0.5 \mathrm{M} \mathrm{CoSO}_{4}+0.3 \mathrm{M} \mathrm{FeSO}_{4}+0.3 \mathrm{M} \mathrm{H}_{3} \mathrm{BO}_{3}+0.25 \mathrm{MC}_{6} \mathrm{H}_{8} \mathrm{O}_{6}$ electrodeposition in the potential $-1.0 \mathrm{~V}$; the height of wires about $10 \mu \mathrm{m}$

Increasing the diameter of the iron wires and the distance between them affects the magnetic properties. There was a decrease in the field of coercivity and a slight decrease in magnetic anisotropy. This may be due to dipolar interactions in the arrays of wire which becomes stronger as their diameter increases. A decrease of pore diameter has the effect of causing a reduction in dipolar interactions between wires and thus an increase in the field of coercivity.

The reduction of the coercive field, the remanence and the remanence squareness $M_{r} / M_{s}$ with the increase of pore diameter wires in other systems was also observed by Kac for Co system [6], and Khan and Petrikowski [22] for CoFe system.

Table 3. The values characterizing the magnetic properties of the Fe NWs obtained by the electrodeposition in the alumina membrane of different pores diameter: $L=$ const $=10 \mu \mathrm{m}$

\begin{tabular}{|c|c|c|c|c|c|c|c|c|c|c|}
\hline \multirow{3}{*}{$\begin{array}{c}D_{p} \\
{[\mathrm{~nm}]}\end{array}$} & \multicolumn{2}{|c|}{$\begin{array}{c}\text { Remanent en- } \\
\text { ergy density } \\
\mu_{0} M_{r} \cdot H_{c} \\
{\left[\mathrm{~kJ} / \mathrm{m}^{3}\right]}\end{array}$} & \multicolumn{2}{|c|}{$\begin{array}{c}\text { Remanence energy } \\
\mu_{0} M_{r} \cdot H_{c} \cdot V \\
{[J]}\end{array}$} & \multicolumn{2}{|c|}{$M_{r} / M_{s}$} & \multicolumn{2}{|c|}{$\begin{array}{c}\text { Remanence } M_{r} \\
\text { [emu/cm }{ }^{3} \text { ] }\end{array}$} & \multicolumn{2}{|c|}{$\begin{array}{c}\text { Coercivity } \\
H_{c} \\
{[\mathrm{kA} / \mathrm{m}]}\end{array}$} \\
\hline & (II) & $(\perp)$ & $\begin{array}{c}(\text { III) } \\
\times 10^{-16}\end{array}$ & $\begin{array}{c}(\perp) \\
\times 10^{-16}\end{array}$ & (II) & $(\perp)$ & (II) & $(\perp)$ & (II) & $(\perp)$ \\
\hline & \multicolumn{10}{|c|}{ to wire axis } \\
\hline 70 & 28.4 & 5.8 & $\begin{array}{c}109 \\
(6.8 \mathrm{keV})\end{array}$ & $\begin{array}{c}2.22 \\
(1.4 \mathrm{keV})\end{array}$ & 0.48 & 0.10 & 826 & 168 & $\begin{array}{c}27.5 \\
(344 \text { Oe) }\end{array}$ & $\begin{array}{c}27.5 \\
(344 \text { Oe) }\end{array}$ \\
\hline 100 & 13.9 & 3.26 & $\begin{array}{c}109 \\
(6.8 \mathrm{keV})\end{array}$ & $\begin{array}{c}2.56 \\
(1.6 \mathrm{keV})\end{array}$ & 0.29 & 0.1 & 462 & 194 & $\begin{array}{c}22.6 \\
(283 \text { Oe })\end{array}$ & $\begin{array}{c}15.9 \\
(199 \text { Oe) }\end{array}$ \\
\hline
\end{tabular}


The studies indicate that small pore diameter, low cathodic potential (small height) are optimal for obtaining samples with large coercivity along the wire axis.

\section{Conclusions}

The Fe nanowire arrays prepared into anodic alumina membranes with different pore diameters and electrodeposited under various cathodic potentials were investigated. The diffraction analysis of iron nanowires indicates the presence of the Fe phase of the Body Centered Cubic lattice with a strong reflection originated from the phase (110). The SEM images of the cross-section revealed well defined nanowires with the smooth lateral surface. The measurements showed that both the impact of the applied potential of deposition and membrane parameters (pore diameter) on magnetization characteristics is low. However, the performed studies allowed us to determine the deposition potential and dimensions of wires optimal for obtaining Fe nanowires with beneficial magnetic characteristics. We find that small diameters of nanowires and low cathodic potential are optimal to produce nanowires with magnetic anisotropy with an easy axis along the nanowire and a high coercivity value.

\section{Acknowledgements}

This research was supported by the Polish Ministry of Science and Higher Education under project No. 10.10.180.307.

\section{References}

[1] Cortés A., Lavín R., Denardin J.C., Marotti R.E., Dalchiele E.A., Valdivia P., Gómez H.: Template assisted electrochemical growth of cobalt nanowires: Influence of deposition conditions on structural, optical and magnetic properties. Journal of Nanoscience and Nanotechnology, 11 (2011), 3899-3910

[2] Cui Y., Lieber C.M.: Functional nanoscale electronic devices assembled using silicon nanowire building blocks. Science, 291, 5505 (2001), 851-853

[3] Sellmyer D., Zheng M., Skomski R.: Magnetism of Fe, Co and Ni nanowires in self-assembled arrays. Journal of Physics: Condensed Matter, 13, 25 (2001), R433-R460

[4] Sellmyer D.J., Zheng H., Yan M., Sun S., Liu Y.: Handbook of Advanced Magnetic Materials. IV: Properties and Application, 2006

[5] Choi J., Sauer G., Göring P., Nielsch K., Wehrspohn R.B., Gösle U.: Monodisperse metal nanowire arrays on Si by integration of template synthesis with silicon technology. Journal of Materials Chemistry, 13, 5 (2003), 1100

[6] Kac M., Zarzycki A., Kac S., Kopec M., Perzanowski M., Dutkiewicz E.M., Suchanek K., Maximenko A., Marszalek M.: Effect of the template-assisted electrodeposition parameters on the structure and magnetic properties of Co nanowire arrays. Materials Science and Engineering: B, 211 (2016), 75-84

[7] Kröll M., Blau W.J., Grandjean D., Benfield R.E., Luis F., Paulus P.M., de Jongh L.J.: Magnetic properties of ferromagnetic nanowires embedded in nanoporous alumina membranes. Journal of Magnetism and Magnetic Materials, 249, 12 (2002), 241-245 
[8] Ciuculescu-Pradines D., Dumestre F., Comesaña-Hermo M., Chaudret B., Spasova M., Farle M., Amiens C.: Single-Crystalline Co Nanowires: Synthesis, Thermal Stability, and Carbon Coating. Chemistry of Materials, 21, 17 (2009), 3987-3995

[9] Rivas J., Kazadi Mukenga Bantu A., Zaragoza G., Blanco M.C., López Quintela M.A.: Preparation and magnetic behavior of arrays of electrodeposited Co nanowires. Journal of Magnetism and Magnetic Materials, 249, 1-2 (2002), 220-227

[10] Ye Z., Liu H., Luo Z., Lee H.-G., Wu W., Naugle D.G., Lyuksyutov I.F.: Thickness dependence of the microstructures and magnetic properties of electroplated Co nanowires. Nanotechnology, 20, 4 (2009), 045704

[11] Ren Y., Liu Q.F., Li S.L., Wang J.B., Han X.H.: The effect of structure on magnetic properties of Co nanowire arrays. Journal of Magnetism and Magnetic Materials, 321, 3 (2009), 226-230

[12] Kaur D., Chaudhary S., Pandya D.K.: Manifestations in the magnetization of the hcp-Co nanowires due to interdependence of aspect ratio and c-axis orientation. Journal of Applied Physics, 114, 4 (2013), 043909

[13] Fert A., Piraux L.: Magnetic nanowires. Journal of Magnetism and Magnetic Materials, 200, 1-3 (1999), 338-358

[14] Cui C.X., Wang B.L., Yang W., Sun J.B.: Effect of deposition voltage and $\mathrm{Co}^{2+}$ concentration on the texture and magnetic properties of Co nanowire arrays. Journal of Crystal Growth, 324, 1 (2011), 168-171

[15] Han X., Liu Q., Wang J., Li S., Ren Y., Liu R., Li F.: Influence of crystal orientation on magnetic properties of hcp Co nanowire arrays. Journal of Physics D Applied Physics, 42, 9 (2009) 095005

[16] Li F., Wang T., Ren L., Sun J.: Structure and magnetic properties of Co nanowires in self-assembled arrays. Journal of Physics: Condensed Matter, 16, 45 (2004), 8053-8060

[17] Haehnel V., Fähler S., Schaaf P., Miglierini M., Mickel C., Schultz L., Schlörb H.: Towards smooth and pure iron nanowires grown by electrodeposition in self-organized alumina membranes. Acta Materialia, 58, 7 (2010), 2330-2337

[18] Hu H.N., Chen H.Y., Yu S.Y., Chen J.L., Wu G.H., Meng F.B., Qu J.P., Li Y.X., Zhu H., Xiao J.Q.: Textured Co nanowire arrays with controlled magnetization direction. Journal of Magnetism and Magnetic Materials, 295, 3 (2005), 257-262

[19] Paulus P.M., Luis F., Kröll M., Schmid G., de Jongh L.J.: Low-temperature study of the magnetization reversal and magnetic anisotropy of $\mathrm{Fe}, \mathrm{Ni}$, and $\mathrm{Co}$ nanowires. Journal of Magnetism and Magnetic Materials, 224, 2 (2001), 180-196

[20] Gumowska W., Dobosz I., Uhlemann M., Koza J.A.: $\mathrm{Al}_{2} \mathrm{O}_{3}-\mathrm{Co}$ and $\mathrm{Al}_{2} \mathrm{O}_{3}-$ Fe composites obtained by the electrochemical method. Archives of Metallurgy and Materials, 54, 4 (2009), 1119-1133

[21] Dobosz I.: Elektrochemiczne metody otrzymywania kompozytów tlenek aluminium - metal (stop) o własnościach magnetycznych. PhD thesis, AGH, Kraków 2011

[22] Khan H.R., Petrikowski K.: Synthesis and properties of the arrays of magnetic nanowires of Co and CoFe. Materials Science and Engineering: C, 19, 1-2, (2002), 345-348 